\title{
Therapeutic Angiogenesis
}

\author{
A Single Intraarterial Bolus of Vascular Endothelial Growth Factor \\ Augments Revascularization in a Rabbit Ischemic Hind Limb Model
}

\author{
Satoshi Takeshita, * Lu P. Zheng, " Edi Brogi, * Marianne Kearney, ${ }^{*}$ Li-Qun Pu, ${ }^{\star}$ Stuart Bunting, ${ }^{3}$ Napoleone Ferrara," \\ James F. Symes, * and Jeffrey M. Isner* \\ *Departments of Medicine (Cardiology), Surgery (Cardiovascular), and Biomedical Research, St. Elizabeth's Medical Center, Tufts \\ University School of Medicine, Boston, Massachusetts 02135; ' Department of Surgery, Royal Victoria Hospital, McGill University, \\ Montreal, Quebec H3A 1A1, Canada; and ${ }^{\S}$ Department of Cardiovascular Research, Genentech Inc., \\ South San Francisco, California 94080
}

\begin{abstract}
Vascular endothelial growth factor (VEGF) is a heparin-binding, endothelial cell-specific mitogen. Previous studies have suggested that VEGF is a regulator of naturally occurring physiologic and pathologic angiogenesis. In this study we investigated the hypothesis that the angiogenic potential of VEGF is sufficient to constitute a therapeutic effect. The soluble 165amino acid isoform of VEGF was administered as a single intraarterial bolus to the internal iliac artery of rabbits in which the ipsilateral femoral artery was excised to induce severe, unilateral hind limb ischemia. Doses of 500-1,000 $\mu \mathrm{g}$ of VEGF produced statistically significant augmentation of collateral vessel development by angiography as well as the number of capillaries by histology; consequent amelioration of the hemodynamic deficit in the ischemic limb was significantly greater in animals receiving VEGF than in nontreated controls (calf blood pressure ratio, $0.75 \pm 0.14$ vs. $0.48 \pm 0.19, P<0.05$ ). Serial angiograms disclosed progressive linear extension of the collateral artery of origin ( stem artery) to the distal point of parent vessel (reentry artery) reconstitution in seven of nine VEGF-treated animals. These findings establish proof of principle for the concept that the angiogenic activity of VEGF is sufficiently potent to achieve therapeutic benefit. Such a strategy might ultimately be applicable to patients with severe limb ischemia secondary to arterial occlusive disease. (J. Clin. Invest. 1994. 93:662670.) Key words: collateral arteries $\bullet$ endothelial cell $\bullet$ peripheral arteries $\bullet$ angiography $\bullet$ capillaries
\end{abstract}

\section{Introduction}

Vascular endothelial growth factor (VEGF) ${ }^{1}$ is a $45-\mathrm{kD}$ heparin-binding dimeric glycoprotein that is mitogenic for endothelial cells (1). VEGF is distinguished from other heparin-binding, angiogenic factors by several features. First, because its

Address correspondence to Dr. Jeffrey M. Isner, St. Elizabeth's Medical Center, 736 Cambridge Street, Boston, MA 02135.

Received for publication 14 July 1993 and in revised form 28 September 1993.

1. Abbreviations used in this paper: bFGF, basic fibroblast growth factor; VEGF, vascular endothelial growth factor.

J. Clin. Invest.

(c) The American Society for Clinical Investigation, Inc.

0021-9738/94/02/0662/09 \$2.00

Volume 93, February 1994, 662-670
$\mathrm{NH}_{2}$ terminus is preceded by a typical signal sequence, VEGF can be secreted by intact cells (2). Second, its binding sites, shown recently to include the tyrosine kinase receptors flt (3), $f l k-1$ (4), and KDR (5), are present in endothelial cells, quiescent as well as proliferating, but not in other cell types. Consequently, VEGF has been regarded as an endothelial cell-specific mitogen (6-8).

Four different homodimeric species of VEGF have been identified, each monomer having 121, 165, 189, or 206 amino acids, respectively $(9,10)$. Alternative splicing of the VEGF transcript, rather than transcription from different genes, is the most likely explanation for the existence of such multiple forms. While all four isoforms display activity in a Miles type of assay (11), i.e., extravasation of Evans blue dye in response to an intradermal injection, these four forms differ in their solubility characteristics. $\mathrm{VEGF}_{121}$ and $\mathrm{VEGF}_{165}$ are diffusible after secretion; VEGF $_{189}$ and VEGF $_{206}$ are secreted but are bound to heparin-containing proteoglycans in the cell surface or basement membrane (12), and thus tend to remain cell associated (1).

VEGF mRNA is expressed in a variety of abundantly vascularized tissues. Furthermore, VEGF and VEGF receptors colocalize with sites of neovascularization in the female reproductive tract of rodents and primates (13-15); these observations were interpreted to suggest a role for VEGF in natural angiogenic processes within the female reproductive system. A similar temporal and spatial relationship has been observed between the ventricular neuroectoderm and capillaries from the perineural plexus in the mouse embryo (16), and in highly vascularized human tumors (17-20).

Evidence that VEGF stimulates angiogenesis in vivo consists principally of experiments performed on rat and rabbit cornea $(21,22)$, the chorioallantoic membrane $(6)$, and the rabbit bone graft model (22). The angiogenic potential of VEGF was further inferred from studies in nude mice demonstrating that VEGF expression conferred upon Chinese hamster ovary cells the ability to form tumors (23), and experiments in which monoclonal antibodies to VEGF were shown to inhibit tumor growth (24).

Whether the magnitude of angiogenesis stimulated by VEGF in vivo is sufficient to constitute a potential therapeutic effect has not been previously tested. Accordingly, this investigation was designed to test the hypothesis that administration of VEGF in the setting of experimentally induced hind limb ischemia could stimulate angiogenesis and thereby modulate the hemodynamic deficit in the ischemic limb. The outcome of these in vivo experiments, performed in a rabbit model, suggests that a single intraarterial bolus of the 165-amino acid 
isoform of VEGF may have clinical use in the treatment of lower limb vascular insufficiency.

\section{Methods}

Animal model. The angiogenic response to intraarterial administration of VEGF in vascular insufficiency was investigated using a rabbit ischemic hind limb model (Fig. 1) (25). All protocols were approved by St. Elizabeth's Institutional Animal Care and Use Committee. A total of 16 male New Zealand White rabbits weighing 3-3.5 kg (Pine Acre Rabbitry, Norton, MA) were anesthetized with a mixture of ketamine $(50 \mathrm{mg} / \mathrm{kg})$ and acepromazine $(0.8 \mathrm{mg} / \mathrm{kg})$ after premedication with xylazine $(2.5 \mathrm{mg} / \mathrm{kg})$. A longitudinal incision was then performed, extending inferiorly from the inguinal ligament to a point just proximal to the patella. The limb in which the incision was performed (right vs. left) was determined at random at the time of surgery by the operator. Through this incision, using surgical loops, the femoral artery was dissected free, along its entire length; all branches of the femoral artery, including the inferior epigastric, deep femoral, lateral circumflex, and superficial epigastric arteries, were also dissected free. After further dissecting the popliteal and saphenous arteries distally, the external iliac artery as well as all of the above arteries were ligated ( 4.0 silk; Ethicon, Sommerville, NJ). Finally, the femoral artery was completely excised from its proximal origin as a branch of the external iliac artery, to the point distally where it bifurcates to form the saphenous and popliteal arteries.

Postoperation, all animals were closely monitored. Analgesia (60 $\mathrm{mg} / \mathrm{kg}$ levorphanol tartrate; Roche Laboratories, Nutley, $\mathrm{NJ}$ ) was administered subcutaneously as required for evidence of discomfort throughout the duration of the experiment. Prophylactic antibiotics ( $15 \mathrm{mg} / \mathrm{kg}$ sulfamethoxazole and $3 \mathrm{mg} / \mathrm{kg}$ trimethoprim; Elkins-Sinn, Cherry Hill, NJ) were also administered subcutaneously for a total of 5 d postoperatively.

Intraarterial VEGF administration. The 165 -amino acid homodimeric species of recombinant human VEGF $\left(\operatorname{rhVEGF}_{165}\right)$ was purified from transfected Chinese hamster ovary cells as previously described (26). The purity of the material was assessed by a silver-stained SDS/ PAGE gel and by the presence of a single $\mathrm{NH}_{2}$-terminal amino acid sequence.

At day 10 postoperation animals received VEGF or vehicle alone (saline with $0.1 \%$ rabbit serum albumin; Sigma Chemical Co., St. Louis, MO), in both cases delivered intraarterially. After performing a baseline angiogram ( see below), a 3-French end-hole infusion catheter (Tracker-18 ${ }^{\mathrm{TM}}$; Target Therapeutics, San Jose, CA) was positioned in the internal iliac artery of the ischemic limb, and then washed with $3 \mathrm{ml}$ of saline containing $0.1 \%$ albumin. Next, either $500 \mu \mathrm{g}(n=4)$ or 1,000 $\mu \mathrm{g}(n=5)$ of VEGF in $5 \mathrm{ml}$ of saline containing $0.1 \%$ albumin was selectively delivered into the internal iliac artery as a bolus over a period of $1 \mathrm{~min}$. Sham-treated animals, receiving an identical volume of saline with $0.1 \%$ albumin, but without VEGF protein, administered over $1 \mathrm{~min}$, were used as controls $(n=7)$.

Evaluation of angiogenesis in the ischemic limb. Development of collateral vessels in the ischemic limb was serially evaluated by calf blood pressure measurement and internal iliac arteriography immediately before treatment (day 10 postsurgery), and then in serial fashion at days 20 and 40 postsurgery (i.e., 10 and $30 \mathrm{~d}$, respectively, postadministration of VEGF or vehicle control). On each occasion, it was necessary to lightly anesthetize the animal with a mixture of ketamine $(10 \mathrm{mg} / \mathrm{kg})$ and acepromazine $(0.16 \mathrm{mg} / \mathrm{kg})$ after premedication with xylazine $(2.5 \mathrm{mg} / \mathrm{kg})$. In the case of blood pressure measurements, pressure recorded from the contralateral, nonischemic limb controlled for any anesthesia-related fluctuations in blood pressure recordings. After the final 40-d angiogram, the animal was killed and tissue sections were prepared from the hind limb muscles in order to perform analysis of capillary density. These analyses were performed for both the control and VEGF-treated groups in relationship to surgery as follows. Control: day 0, surgery; day 10, BP/angio/saline; day 20, BP/an- gio; day 40, BP/angio/autopsy. VEGF treated: day 0, surgery; day 10 , BP/angio/VEGF; day 20, BP/angio; day 40, BP/angio/autopsy.

Lower limb calf blood pressure ratio. Calf blood pressure was measured in both hind limbs using a Doppler Flowmeter (1050; Parks Medical Electronics, Aloha, OR), immediately before treatment (day 10 ), as well as on days 20 and 40 . On each occasion, the hind limbs were shaved and cleaned, the pulse of the posterior tibial artery was identified using a Doppler probe, and the systolic blood pressures of both limbs were determined using standard techniques. Briefly, a 2.5cm-wide cuff was applied over the upper calf, and the Doppler probe was placed over the posterior tibial artery. The cuff was inflated rapidly to $\sim 30 \mathrm{mmHg}$ above the anticipated systolic pressure. The cuff was then deflated slowly, no faster than $3 \mathrm{~mm} \mathrm{Hg} / \mathrm{s}$. The first appearance of the Doppler flow signal (phase I) was recorded as the systolic pressure. Care was taken to prevent the rubber component of the cuff balloon from extending beyond its covering, and to prevent central ballooning due to loose cuff placement. All measurements were performed by a single observer blinded to the treatment regimen. The calf blood pressure ratio was defined for each rabbit as the ratio of systolic pressure of the ischemic limb to systolic pressure of the normal limb.

Selective internal iliac arteriography. Collateral artery development in this ischemic hind limb model originates from the internal iliac artery. Accordingly, selective internal iliac arteriography was performed on day 10 (before initiation of therapy), and again on days 20 and 40 . The 3-French infusion catheter (Tracker- $18^{\mathrm{TM}}$ ) was introduced into the right common carotid artery through a small cutdown, and advanced to the internal iliac artery of the ischemic limb using a 0.014-in guidewire (Hi-Torque Floppy II; Advanced Cardiovascular Systems, Temecula, CA) under fluoroscopic guidance. The tip of the catheter was positioned in the internal iliac artery at the level of the interspace between the seventh lumbar and the first sacral vertebrae. After intraarterial injection of nitroglycerin $(0.25 \mathrm{mg}$; SoloPak Laboratories, Franklin Park, IL), a total of $5 \mathrm{ml}$ of contrast media (Isovue370; Squibb Diagnostics, New Brunswick, NJ) was then injected using an automated angiographic injector (Medrad, Pittsburgh, PA) at a rate of $1 \mathrm{ml} / \mathrm{s}$. Serial images of the ischemic hind limb were then recorded on $105-\mathrm{mm}$ spot film at a rate of one film per second for at least $10 \mathrm{~s}$. After completion of arteriography, the catheter was removed and the wound was closed. All of the above-described procedures were completed without the use of heparin.

Quantitative angiographic analysis of collateral vessel development was performed as follows. A composite of $5-\mathrm{mm}^{2}$ grids was placed over the medial thigh area of the 4-s angiogram. The total number of grid intersections in the medial thigh area, as well as the total number of intersections crossed by a contrast-opacified artery, were counted individually by a single observer blinded to the treatment regimen. An angiographic score was calculated for each film as the ratio of grid intersections crossed by opacified arteries divided by the total number of grid intersections in the medial thigh.

Capillary density and capillary/muscle fiber ratio. The effect of VEGF upon anatomic evidence of collateral artery formation was further examined by measuring the number of capillaries in light microscopic sections taken from the ischemic hind limbs. Tissue specimens were obtained as transverse sections from the adductor muscle and the semimembranous muscle of the ischemic limb of each animal at the time of death (day 40). These two muscles were chosen for light microscopic analysis because: $(a)$ they are the major muscles of the medial thigh, and $(b)$ each was originally perfused by the deep femoral artery, ligated at the time that the common/superficial femoral artery was excised. Muscle samples were embedded in O.C.T. compound (Miles Inc., Elkhart, IN) and snap-frozen in liquid nitrogen. Multiple frozen sections ( $5 \mu \mathrm{m}$ in thickness) were then cut from each specimen on a cryostat (Miles Inc.), so that the muscle fibers were oriented in a transverse fashion, and two sections were then placed on glass slides. Tissue sections were stained for alkaline phosphatase using an indoxyl-tetrazolium method to detect capillary endothelial cells, as previously described (27-29), and were then counterstained with eosin. Capillaries were counted under a $\times 20$ objective to determine the capillary density 
(mean number of capillaries $/ \mathrm{mm}^{2}$ ). A total of 20 different fields from the two muscles were randomly selected, and the number of capillaries were counted. To ensure that analysis of capillary density was not overestimated due to muscle atrophy, or underestimated due to interstitial edema, capillaries identified at necropsy were also evaluated as a function of muscle fibers in the histologic section. The counting scheme used to compute the capillary/muscle fiber ratio was otherwise identical to that used to compute capillary density.

Statistics. Results were expressed as mean \pm SD. Statistical significance was evaluated using an unpaired Student's $t$ test for comparisons between two means, an analysis of variance followed by Scheffe's procedure for more than two means, a $\chi^{2}$ test for categorical data, and a linear regression test to compare angiographic scores at days 10 and 20 . A value of $P<0.05$ was interpreted to denote statistical significance.

\section{Results}

Lower limb calf blood pressure ratio. At day 10 postoperation, the Doppler flow signal from the posterior tibial artery could not be detected in most rabbits in either the VEGF-treated or control group due to the severity of ischemia induced. Even when present in occasional rabbits, the signal was generally insufficient to allow accurate blood pressure measurement. For both groups, the blood pressure ratio at day 10 was therefore referred to as zero, indicating severe but virtually identical ischemia in both groups before treatment. By day 20, a Doppler flow signal generally became evident in both groups of animals;

a
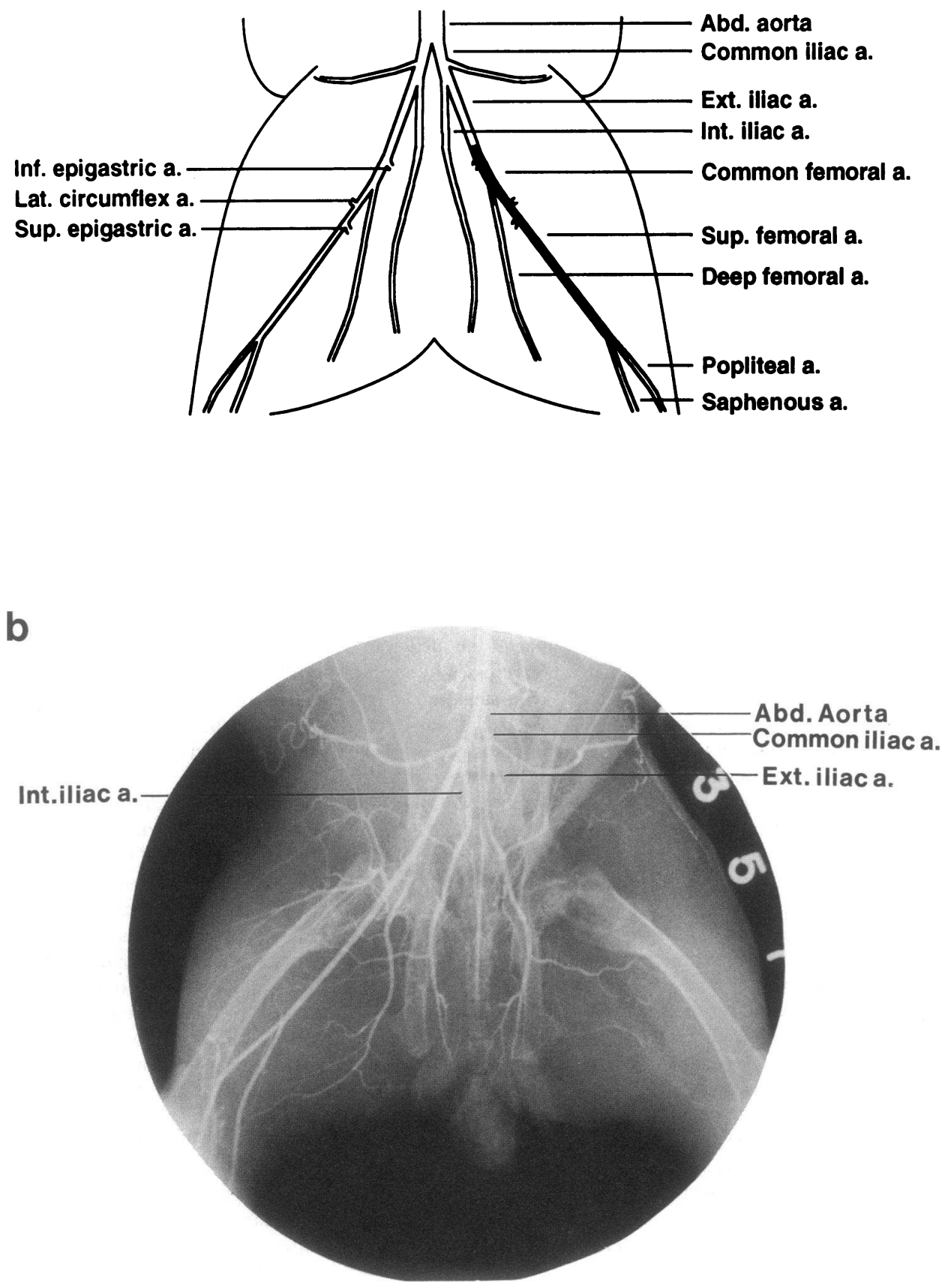

Figure 1. Rabbit ischemic hind limb model. (a) All shaded vessels are ligated and excised. $(b)$ Aortic angiography performed immediately after surgery (day 0 ). 
at this time, the blood pressure ratio for animals in the VEGFtreated group, however, was significantly higher than for animals in the control group $(0.54 \pm 0.15$ vs. $0.25 \pm 0.25, P<0.05)$. At day 40, the blood pressure ratio was further improved significantly in the VEGF-treated group $(0.75 \pm 0.14, P<0.01$ vs. day $20)$, but not in the control group $(0.48 \pm 0.19, P=$ NS vs. day 20 ). Moreover, at day 40 , the blood pressure ratio of the VEGF-treated group was significantly higher than that of control group $(P<0.05)$ (Fig. $2 a)$.

Angiographic assessment. Fig. 3 illustrates representative internal iliac angiograms recorded from both control and VEGF-treated animals. In control animals, collateral artery development in the medial thigh typically appeared unchanged or progressed only slightly in serial angiograms recorded at days 10,20 , and 40 (Fig. 3, $a-c$ ). In contrast, in the VEGFtreated group, improvement of collateral artery development was typically observed in angiograms at days 20 and 40 when compared with the baseline (day 10) angiogram (Fig. 3, $d-f$ ). Distal arterial reconstitution, barely apparent in control group (Fig. 3, $b$ and $c$, arrows), was readily seen in the VEGF-treated group (Fig. 3, $e$ and $f$, arrows). Quantitative analysis of collat-

$\mathbf{a}$

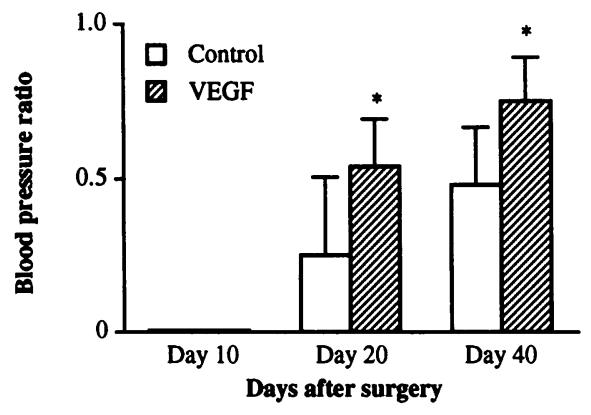

b

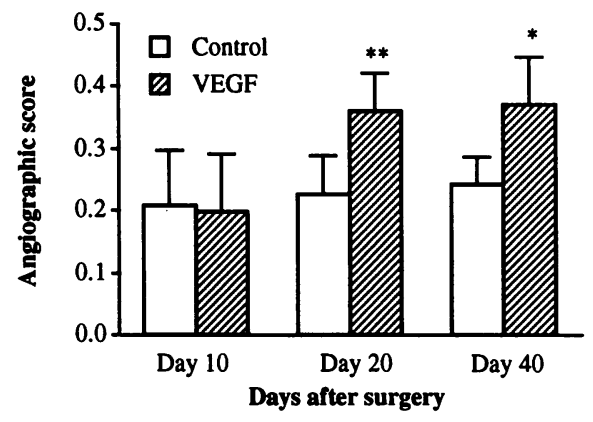

c

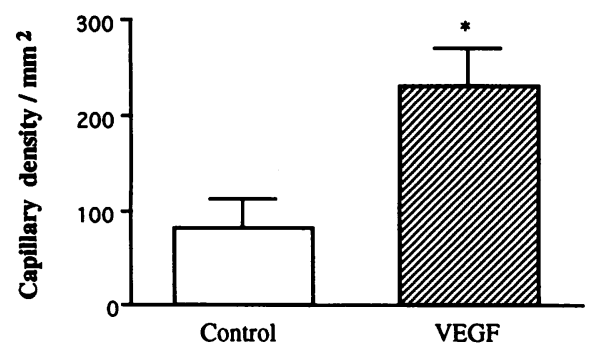

Figure 2. Effect of VEGF on revascularization in ischemic limb model. (a) Calf blood pressure ratio performed at days 10,20, and $40\left({ }^{*} P<0.05\right)$. (b) Angiographic score at days 10,20 , and $40\left({ }^{*} P\right.$ $\left.<0.01,{ }^{* *} P<0.001\right)$. (c) Capillary density $\left(\right.$ per $\left.\mathrm{mm}^{2}\right)$ at day $40\left({ }^{*} P\right.$ $<0.001)$. eral vessel development in the medial thigh was performed by calculating the angiographic score as described above. At baseline (day 10), before treatment, there was no significant difference in angiographic score between the VEGF-treated and control groups $(0.20 \pm 0.09$ vs. $0.21 \pm 0.09, P=N S)$. By days 20 and 40 , however, the angiographic score in VEGF-treated group was significantly higher than that in control group (day 20: $0.36 \pm 0.06$ vs. $0.23 \pm 0.06, P<0.001$; day $40: 0.37 \pm 0.08$ vs. $0.24 \pm 0.05, P<0.01$ ) (Fig. $2 b$ ). Although a progressive increase in angiographic score was observed between days 10 and 40 in both groups, that measured for the control group was not statistically significant. The increase calculated for the VEGFtreated group was significant between days 10 and 20 ( $P$ $<0.001$ ), but not between days 20 and 40. As shown in Fig. 4 $b$, the magnitude of improvement in angiographic score was not dependent upon the dose ( 500 or $1,000 \mu \mathrm{g}$ ) of VEGF used. Instead, the increase in angiographic score at day 20 was inversely related to the angiographic score at the time of VEGF administration (day 10) $(r=-0.97, P<0.001)$. Although a similar relationship was observed in control group (Fig. $4 a$ ), the magnitude of improvement in angiographic score at day 20 was small even in those animals having a low angiographic score at baseline (day 10) $(r=-0.73, P=0.06)$. In both groups, the morphology of the augmented collateral circulation included fine networks of so-called mid-zone collateral vessels (30) (Fig. 3). In addition, serial angiograms disclosed progressive linear extension of the stem (internal iliac) artery to the reentry (popliteal or saphenous arteries) in seven $(78 \%)$ of the nine VEGF-treated animals. In contrast, such direct linear extension was observed in only two $(29 \%)$ of seven controls ( $P$ $<0.05$ ) (Fig. 3, b, c, e, and $f$, open arrows).

Capillary density and capillary/muscle fiber ratio. To further evaluate the effect of intraarterial VEGF administration upon revascularization of the ischemic hind limb, the medial thigh muscles of the ischemic limbs were histologically examined at day 40 as described above. For muscles in the VEGFtreated group, capillary density measured 2.5 times that measured for the control group $\left(230.8 \pm 39.1\right.$ vs. $83.1 \pm 31.4 / \mathrm{mm}^{2}, P$ $<0.001$ ) (Fig. $2 c$ ). Analysis of capillary/muscle fiber ratio disclosed a value of $0.76 \pm 0.06$ in the VEGF-treated group vs. $0.36 \pm 0.08$ in the control group $(P<0.001)$. Light microscopic signs of frank myonecrosis were not observed in either group.

\section{Discussion}

The therapeutic implications of angiogenic growth factors were defined by the pioneering work of Folkman and colleagues over two decades ago (31). Their work documented the extent to which tumor development was dependent upon neovascularization and suggested that this relationship might involve angiogenic growth factors that were specific for neoplasms. Subsequent studies established that a common group of polypeptide growth factors were responsible for natural as well as pathologic angiogenesis.

The identification and characterization of VEGF followed a similar course. Initially isolated as a heparin-binding secreted factor from bovine pituitary folliculo-stellate cells (6), VEGF was also purified independently as a tumor-secreted factor that induced vascular permeability by the Miles assay $(32,33)$. Data accumulated from a variety of previous studies support the role of VEGF in embryogenesis (4), wound healing (19), and ovulation (13-15). Recent experimental work performed 

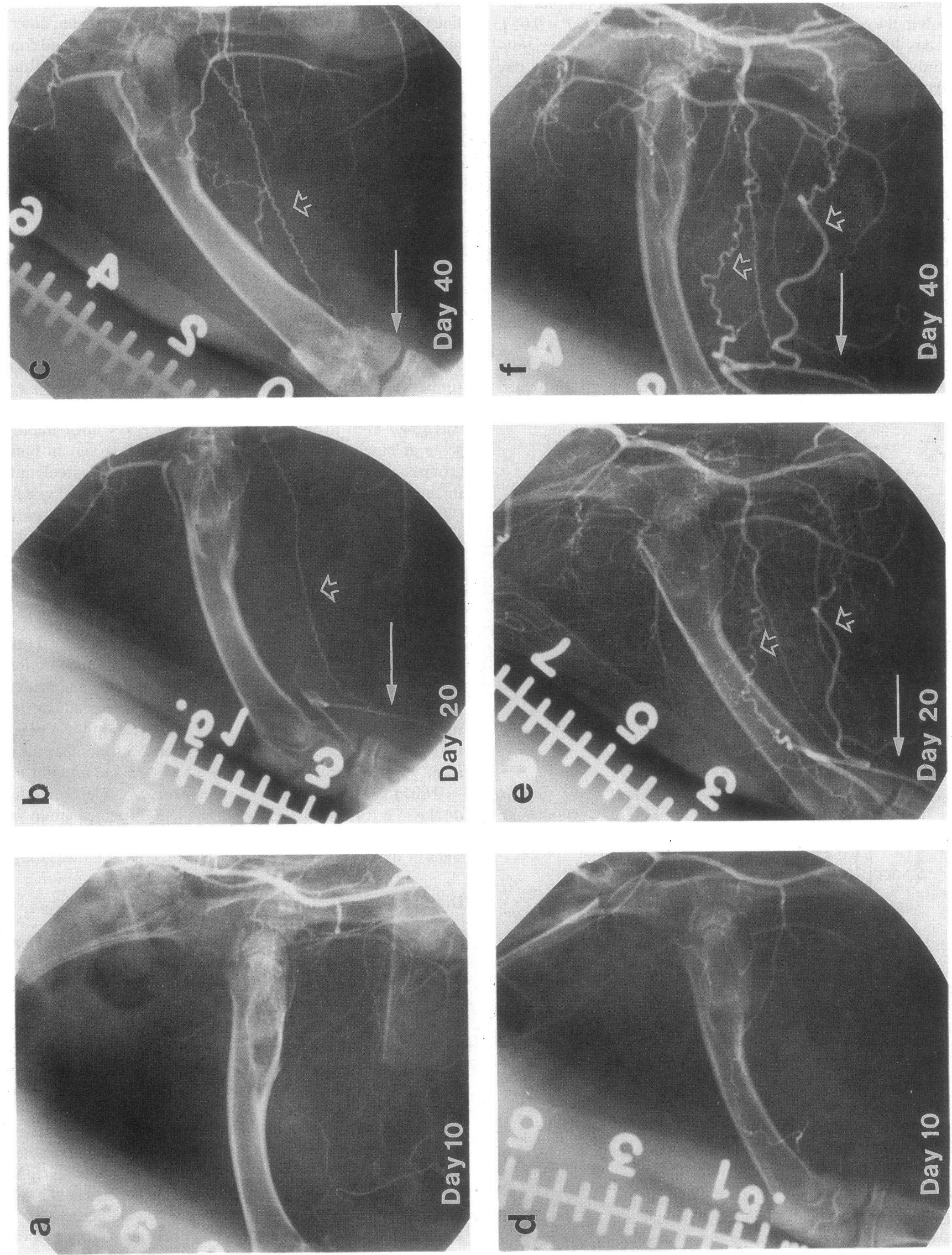
a

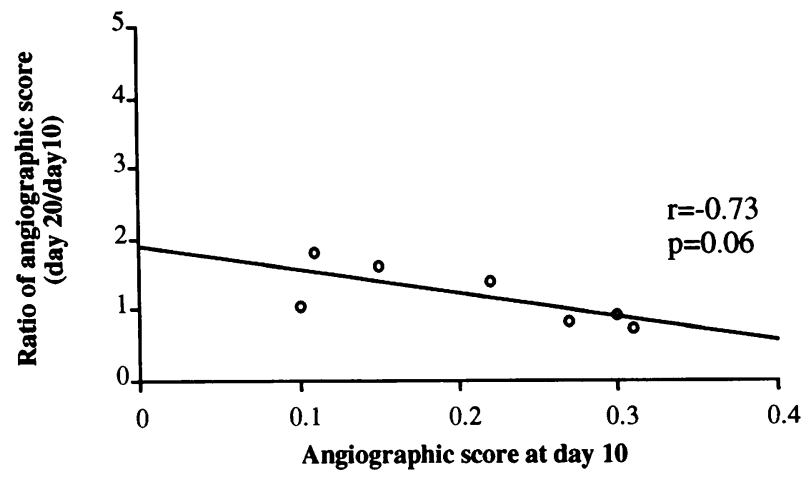

b

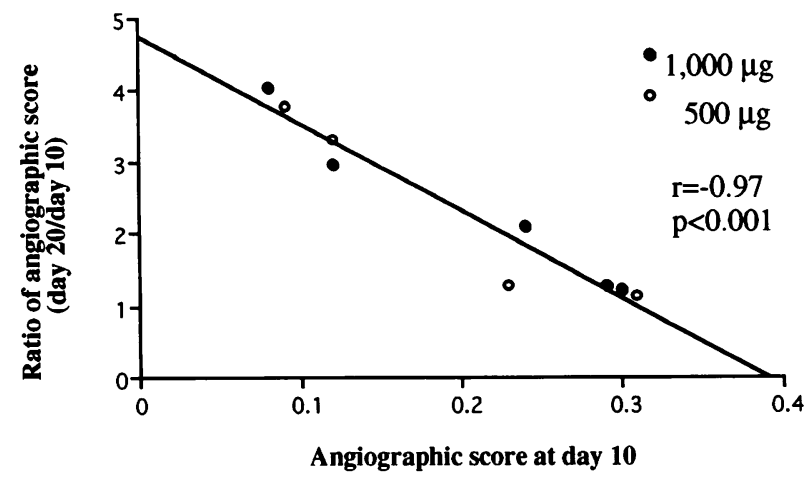

Figure 4. Baseline angiographic score (day 10) and the magnitude of collateral vessel development at day 20: ratio of angiographic score (day 20/day 10). (a) Control group and (b) VEGF-treated group.

with monoclonal antibodies to VEGF (24) has suggested the potential role of VEGF in tumor growth in vivo. The present findings extend these previous observations by establishing a potential therapeutic role for VEGF in the treatment of arterial insufficiency.

The experimental model (25) used in this study was designed to simulate ischemia characteristic of patients with severe lower extremity arterial occlusive disease. In contrast to models of acute ischemic injury $(29,34)$, an interval of $10 \mathrm{~d}$ between the time of surgery and initiation of administration of VEGF was incorporated to allow for endogenous recovery and stabilization. Baseline angiography documented that this 10-d interval was sufficient for development of varying degrees of spontaneous collateral vessel formation. The notion that the current animal model simulates "chronic" ischemia is further supported by the finding that collateral vessel development did not improve significantly beyond this point, up to the time of final angiography and death at $40 \mathrm{~d}$ (Fig. 3). Indeed, initial studies evaluating this model (25) demonstrated no significant "spontaneous" improvement in collateral perfusion either angiographically or hemodynamically between days 30 and 90 after surgically induced ischemia.
Therapeutic options for patients with lower extremity vascular obstructive disease are limited (35). Such patients are often refractory to conservative measures and typically unresponsive to drug therapy. When vascular obstruction is lengthy and/or widespread, nonsurgical revascularization may not be feasible. Surgical therapy, consisting of arterial bypass and/or amputation, is complicated by a variable morbidity and mortality, and is dependent for its efficacy upon short- and long-term patency of the conduit used. In many patients, the diffuse nature of the disease acts to compromise the results of surgical reconstruction. Therapeutic angiogenesis thus constitutes a potential alternative treatment strategy for such patients.

The strategy used in the current series of experiments was designed to exploit certain features of the 165-amino acid VEGF species, the predominant molecular form found in normal cells and tissues $(9,36)$. Unlike $\operatorname{VEGF}_{189}$ and $\operatorname{VEGF}_{206}$, VEGF $_{165}$ is a soluble protein and therefore suitable for intraarterial bolus delivery. Direct intraarterial administration upstream from the occluded artery would be expected to optimize concentration and activity of VEGF in the local circulation of the affected limb; furthermore, this route of administration would be easily reproduced in human subjects using available drug delivery catheters. Intraarterial delivery, in contrast to previously employed regimens that used repeated daily (for 14 d) intramuscular injections (29), would thus be expected to facilitate trials of human therapy. In this respect, the therapeutic strategy used in this study is similar to that used previously by Yanagisawa-Miwa et al. (34) for the treatment of acute myocardial infarction. In the latter study, a booster dose of basic fibroblast growth factor (bFGF) was required $6 \mathrm{~h}$ after the initial intraarterial dose. Despite the fact that the biological half-life of VEGF is relatively short ( $<6 \mathrm{~min}, \mathrm{~N}$. Ferrara et al., unpublished data), the protracted response to an intraarterial bolus may be feasible if proteoglycan constituents of the extracellular matrix bind VEGF for some undetermined period of time. It should be noted in this regard that while diffusible relative to $\mathrm{VEGF}_{189}$ and $\mathrm{VEGF}_{206}, \mathrm{VEGF}_{165}$ still demonstrates substantial affinity for heparin (more, for example, than VEGF $_{121}$ ); in fact, previously published data by Houck et al. (12) indicate that up to $50 \%$ of $\mathrm{VEGF}_{165}$ is retained extracellularly by heparin-binding proteoglycans.

VEGF contrasts with most previously described angiogenic growth factors in that its high affinity receptors appear limited to endothelial cells. In contrast to other angiogenic growth factors, including acidic and basic FGF, which are known to be mitogenic for smooth muscle cells $(37,38)$ and fibroblasts as well as endothelial cells, the fact that the mitogenic activity of VEGF is limited to endothelial cells constitutes a theoretical advantage for angiogenesis strategies designed to treat vascular insufficiency.

Although heparin is often administered prophylactically during percutaneous arterial catheterization, the use of heparin was explicitly avoided during all diagnostic angiograms and / or catheter-based delivery of VEGF in the current series of experi-

Figure 3. Selective internal iliac angiography of control rabbit performed at $(a)$ day 10 (baseline), $(b)$ day 20 , and $(c)$ day 40 , and of VEGFtreated rabbit at $(d)$ day 10 (baseline), $(e)$ day 20, and $(f)$ day 40. The angiograms shown here yielded angiographic scores of $(a) 0.10,(b)$ $0.11,(c) 0.17,(d) 0.12,(e) 0.36$, and $(f) 0.41$. Distal reconstitution, barely apparent in control group $(b$ and $c$, arrows), was evident in the VEGF-treated group ( $e$ and $f$, arrows). Direct and linear extension of internal iliac artery to popliteal and/or saphenous arteries was also more evident in VEGF-treated group ( $b, c, e$, and $f$, open arrows). 

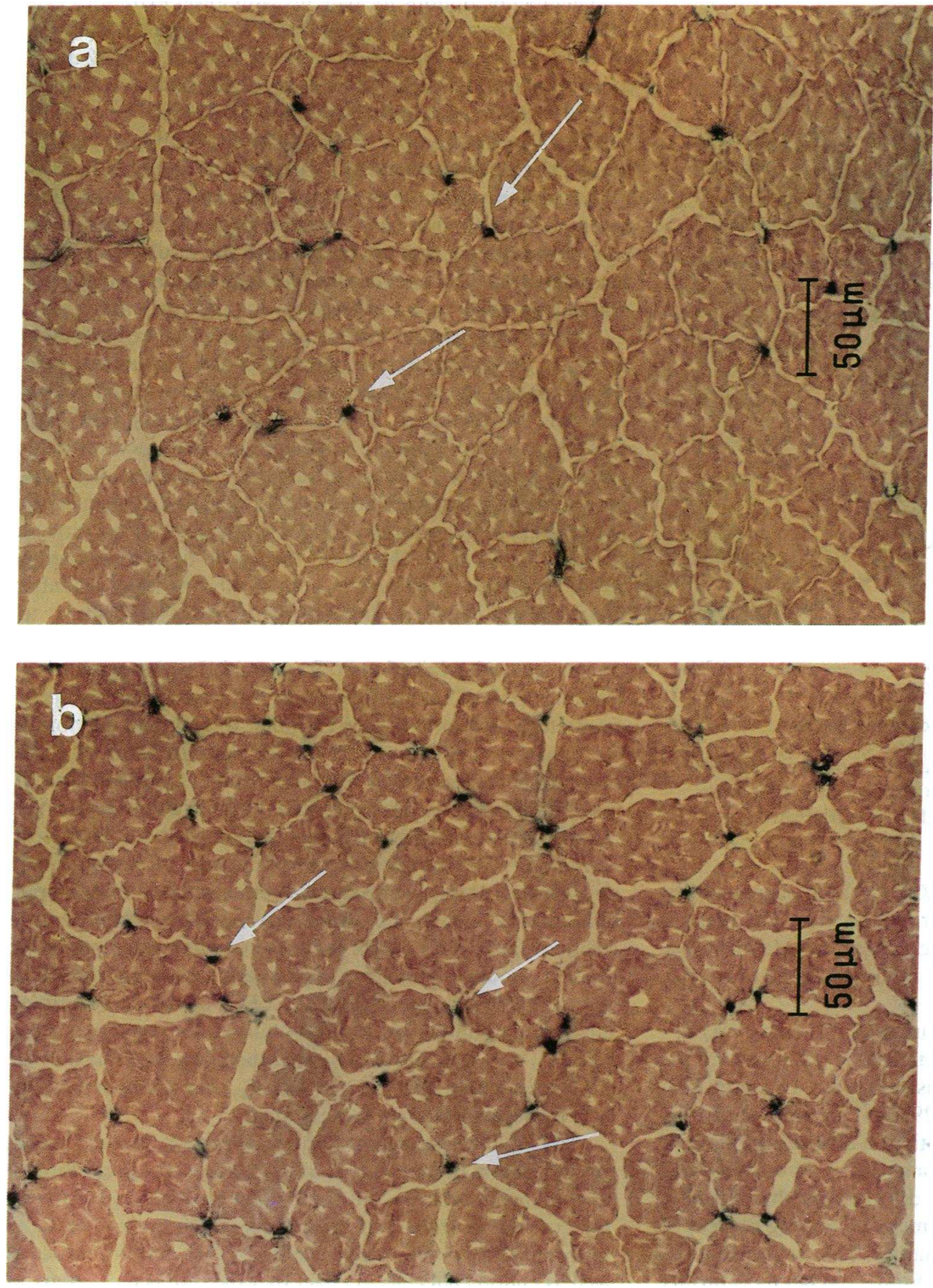

Figure 5. Alkaline phosphatase staining of ischemic hind limb muscle harvested at day 40. (a) Control group and $(b)$ VEGF-treated group. Dark blue dots indicate capillaries (arrows) (counterstained with eo$\sin )$. ments. The potential stimulatory effect of heparin on collateral development (39-42), believed to be mediated by release of endogenous bFGF from the extracellular matrix, was thus obviated. It should be noted, however, that omission of heparin may have blunted the full therapeutic impact of VEGF in the current protocol. Recent work by Soker et al. (43) has indicated that circulating $\alpha_{2}$-macroglobulin covalently binds to VEGF; once complexed, VEGF can no longer bind to the VEGF receptors of vascular endothelial cells, and is in essence thereby inactivated. The binding and consequent inactivation of VEGF by $\alpha_{2}$-macroglobulin was completely inhibited by 20 $\mu \mathrm{g} / \mathrm{ml}$ of heparin. Future experiments will evaluate the angio- genic response of VEGF, administered with heparin, in this same animal model.

Evidence of angiogenesis (44) in response to VEGF administration was observed at two levels. Necropsy examination documented an increase in vascularity at the capillary level, consistent with the classical definition of angiogenesis espoused by Klagsbrun and Folkman (44). In addition, systematic quantification of angiographic recordings performed serially at 10 , 20 , and 40-d postoperation demonstrated that development of angiographically visible collateral arteries in the VEGF-treated animals exceeded that observed in the control group, both at days 20 and 40. From an anatomic standpoint, angiographic 
improvement in the treatment group appeared restricted to the $10 \mathrm{~d}$ after administration of VEGF, after which a plateau was observed for the subsequent 20-d period. Moreover, while the number of animals studied and the doses of VEGF used have to date been limited, the magnitude of improvement in angiographic score nevertheless appeared to be independent of the dose of VEGF used; instead, angiographic score improved as a function of the severity of baseline angiopenia. This finding raises the possibility that hypoxia, in addition to upregulating transcription of VEGF mRNA (45), may also result in upregulation of endothelial cell receptors for VEGF. A similar relationship, albeit with a much flatter slope, was demonstrated for the control animals, in which the ultimate increase in angiographic score was far more limited. The principal angiographic finding accounting for the increase in angiographic score observed in the VEGF-treated group was an increase in so-called mid-zone collateral vessels ( 30$)$, consistent with the definition of angiogenesis cited above. Furthermore, in most VEGFtreated animals, vs. only a few controls, this was accompanied by progressive linear extension of the artery of origin (stem artery) to the distal point of parent vessel reconstitution (reentry artery). Subsequent study will be required to determine whether this angiographic feature is a distinct consequence of therapeutic vs. natural angiogenesis in this animal model of circulatory insufficiency.

The physiologic correlate of these angiographic findings, and thus the extent to which angiogenesis was therapeutic, was assessed by serial measurement of the lower limb blood pressure ratio. Both at days 20 and 40, this ratio in the VEGFtreated group exceeded significantly the same ratio measured in the control group. The temporal evolution of hemodynamic improvement did not altogether parallel the temporal sequence of improvement in angiographic score noted above. VEGF administration, for example, produced a statistically significant increase in angiographic score between the baseline (day 10) examination and the first follow up angiogram (day 20); this was accompanied by a significant increase in lower limb blood pressure ratio. From days 20 to 40 , VEGF produced no further improvement in angiographic score; during this same period of time, however, calf blood pressure ratio continued to improve to a statistically significant degree. In the control group, serial angiographic examinations failed to show significant improvement in collateral artery development after the baseline study; hemodynamic findings did improve, although never to the significant degree observed in the VEGF-treated animals. The secondary improvement in calf blood pressure ratio between days 20 and 40 in the VEGF-treated group, as well as the more modest improvement shown for the control group, appeared to result from an increase in size, rather than number, of collateral vessels (Fig. 3 ).

This study was not intended to determine the extent of fluid extravasation resulting from VEGF administration, and, accordingly, no tracer studies were included in the experimental design. Light microscopic observations, however, failed to disclose evidence of interstitial edema formation observed in those animals receiving VEGF. Although experimental use of the Miles assay has clearly suggested that VEGF selectively augments vascular permeability $(12,17,32,33)$, the significance of this finding remains unclear pending further analyses.

In summary, the anatomic and physiologic findings observed after administration of VEGF $_{165}$ in an experimental model of circulatory insufficiency establishes proof of principle for the concept that the angiogenic activity of VEGF is sufficiently potent to constitute a therapeutic effect. Further investigation may clarify the extent to which use of VEGF may be appropriate for treatment of selected patients with advanced lower extremity vascular occlusive disease.

\section{Acknowledgments}

We are grateful to Dr. John Ogez for purification of rhVEGF, to Dr. Takayuki Asahara for his assistance with animal experiments, to Ms. Carrie Loushin for her assistance with the histology, and to Ms. Mickey Neely for her secretarial assistance.

This work was supported in part by grants (HL-40518, HL-02824 [J.M.Isner]) from the National Heart, Lung, and Blood Institute, National Institutes of Health.

\section{References}

1. Ferrara, N., K. A. Houck, L. B. Jakeman, J. Winer, and D. W. Leung. 1991. The vascular endothelial growth factor family of polypeptides. J. Cell. Biochem. 47:211-218.

2. Leung, D. W., G. Cachianes, W. J. Kuang, D. V. Goeddel, and N. Ferrara 1989. Vascular endothelial growth factor is a secreted angiogenic mitogen. Science (Wash. DC). 246:1306-1309.

3 deVries, C., J. A. Escobedo, H. Ueno, K. Houck, N. Ferrara, and L. T. Williams. 1992. The $f m s$-like tyrosine kinase, a receptor for vascular endothelial growth factor. Science (Wash. DC). 255:989-991.

4. Millauer, B., S. Wizigmann-Voos, H. Schnurch, R. Martinez, N. P. H. Moller, W. Risau, and A. Ulrich. 1993. High affinity VEGF binding and developmental expression suggest $F l k-1$ as a major regulator of vasculogenesis and angiogenesis. Cell. 72:835-846.

5. Terman, B. I., M. Dougher-Vermozen, M. E. Carrion, D. Dimitrov, D. C. Armellino, D. Gospodarowicz, and P. Böhlen. 1992. Identification of the KDR tyrosine kinase as a receptor for vascular endothelial growth factor. Biochem. Biophys. Res. Commun. 187:1579-1586.

6. Ferrara, N., and W. J. Henzel. 1989. Pituitary follicular cells secrete a novel heparin-binding growth factor specific for vascular endothelial cells. Biochem. Biophys. Res. Commun. 161:851-855.

7. Conn, G., D. Soderman, M-T. Schaeffer, M. Wile, V. B. Hatcher, and K. A. Thomas. 1990. Purification of glycoprotein vascular endothelial cell mitogen from a rat glioma cell line. Proc. Natl. Acad. Sci. USA 87:1323-1327.

8. Ishikawa, F., K. Miyazono, U. Hellman, H. Drexler, C. Westernedt, K. Hagiwara, K. Usuki, F. Takaku, W. Risau, and C-H. Heldin. 1989. Identification of angiogenic activity and the cloning and expression of platelet-derived endothelial cell growth factor. Nature (Lond.). 338:557-561.

9. Tisher, E., R. Mitchell, T. Hartmann, M. Silva, D. Gospodarowicz, J. Fiddes, and J. Abraham. 1991. The human gene for vascular endothelial growth factor. J. Biol. Chem. 266:11947-11954.

10. Houck, K. A., N. Ferrara, J. Winer, G. Cachianes, B. Li, and D. W. Leung. 1991. The vascular endothelial growth factor family: identification of a fourth molecular species and characterization of alternative splicing of RNA. Mol. Endocrinol. 5:1806-1814.

11. Miles, A. A., and E. M. Miles. 1952. Vascular reactions to histamine, histamine liberators or leukotoxins in the skin of the guinea pigs. J. Physiol. 118:228-257.

12. Houck, K. A., D. W. Leung, A. M. Rowland, J. Winer, and N. Ferrara. 1992. Dual regulation of vascular endothelial growth factor bioavailability by genetic and proteolytic mechanisms. J. Biol. Chem. 267:26031-26037.

13. Shweiki, D., A. Itin, G. Neufeld, H. Gitay-Goren, and E. Keshet. 1993. Patterns of expression of vascular endothelial growth factor (VEGF) and VEGF receptors in mice suggest a role in hormonally regulated angiogenesis. J. Clin. Invest. 91:2235-2243.

14. Phillips, H. S., J. Hains, D. W. Leung, and N. Ferrara. 1990. Vascular endothelial growth factor is expressed in rat corpus luteum. Endocrinology. 127:965-968.

15. Ravindranath, N., L. Little-Ihrig, H. S. Phillips, N. Ferrara, and Zeleznick. 1992. Vascular endothelial growth factor mRNA expression in the primate ovary. Endocrinology. 131:254-260.

16. Breier, G., U. Albrecht, S. Sterrer, and W. Risau. 1992. Expression of vascular endothelial growth factor during embryonic angiogenesis and endothelial cell differentiation. Development (Camb.). 114:521-532.

17. Dvorak, H. F., T. M. Sioussat, L. F. Brown, B. Berse, J. A. Nagy, A. Sotrel, E. J. Manseau, L. Van De Water, and D. R. Senger. 1991. Distribution of vascular permeability factor ( vascular endothelial growth factor) in tumors: concentration in tumor blood vessels. J. Exp. Med. 174:1275-1278. 
18. Plate, K. H., G. Breier, H. A. Weich, and W. Risau. 1992. Vascular endothelial growth factor is a potential tumour angiogenesis factor in human gliomas in vivo. Nature (Lond.). 359:845-848.

19. Brown, L. F., K-T. Yeo, B. Berse, T-K. Yeo, D. R. Senger, H. F. Dvorak, and L. Van De Water. 1992. Expression of vascular permeability factor (vascular endothelial growth factor) by epidermal keratinocytes during wound healing. $J$. Exp. Med. 176:1375-1379.

20. Berkman, R. A., M. J. Merrill, W. C. Reinhold, W. T. Monacci, A. Saxena, W. C. Clark, J. T. Robertson, I. U. Ali, and E. H. Oldfield. 1993. Expression of the vascular permeability factor/vascular endothelial growth factor gene in central nervous system neoplasms. J. Clin. Invest. 91:153-159.

21. Levy, A. P., R. Tamargo, H. Brem, and D. Nathans. 1989. An endothelial cell growth factor from the mouse neuroblastoma cell line NB41. Growth Factors. 2:9-19.

22. Connolly, D. T., D. M. Hewelman, R. Nelson, J. V. Olander, B. L. Eppley, J. J. Delfino, R. N. Siegel, R. S. Leimgruber, and J. Feder. 1989. Tumor vascular permeability factor stimulates endothelial cell growth and angiogenesis. J. Clin. Invest. 84:1470-1478

23. Ferrara, N., J. Winer, T. Burton, A. Rowland, M. Siegel, H. S. Phillips, T. Terrell, G. A. Keller, and A. D. Levinson. 1992. Expression of vascular endothelial growth factor does not promote transformation but confers a growth advantage in vivo to Chinese hamster ovary cells. J. Clin. Invest. 91:160-170.

24. Kim, K. J., B. Li, J. Winer, M. Armanini, N. Billett, H. S. Phillips, and N. Ferrara. 1993. Inhibition of vascular endothelial growth factor-induced angiogenesis suppresses tumour growth in vivo. Nature (Lond.). 362:841-844.

25. Pu, L-Q., K. J. Lachapelle, S. Jackson, R. Lisbona, R. Brassard, S. Carpenter, and J. F. Symes. A persistent hind limb ischemia model in the rabbit. $J$. Invest. Surg. In press.

26. Ferrara, N., D. W. Leung, G. Cachianes, J. Winer, and W. J. Henzel. 1991. Purification and cloning of vascular endothelial growth factor secreted by pituitary follicolostellate cells. Methods Enzymol. 198:391-404.

27. Ziada, A. M., O. Hudlicka, K. R. Tyler, and A. J. Wright. 1984. The effect of long-term vasodilation on capillary growth and performenace in rabbit heart and skeletal muscle. Cardiovasc. Res. 18:724-732.

28. Flanagan, M. F., A. M. Fujii, S. D. Colan, R. G. Flanagan, and J. E. Lock 1991. Myocardial angiogenesis and coronary perfusion in left ventricular pressure-overload hypertrophy in the young lamb: evidence for inhibition with chronic protamine administration. Circ. Res. 68:1458-1470.

29. Baffour, R., J. Berman, J. L. Garb, S. W. Rhee, J. Kaufman, and P. Friedmann. 1992. Enhanced angiogenesis and growth of collaterals by in vivo administration of recombinant basic fibroblast growth factor in a rabbit model of acute lower limb ischemia: dose-response effect of basic fibroblast growth factor. J. Vasc. Surg. 16:181-191.

30. Longland, C. J. 1953. The collateral circulation of the limb. Ann. R. Coll. Surg. Engl. 13:161-181.
31. Folkman, J. 1971. Tumor angiogenesis: therapeutic implications. N. Engl. J. Med. 285:1182-1186.

32. Keck, P. J., S. D. Hauser, G. Krivi, K. Sanzo, T. Warren, J. Feder, and D. T. Connolly. 1989. Vascular permeability factor, an endothelial cell mitogen related to PDGF. Science (Wash. DC). 246:1309-1342.

33. Connolly, D. R., J. V. Olander, D. Heuvelman, R. Nelson, R. Monsell, N. Siegel, B. L. Haymore, R. Leimgruber, and J. Feder. 1989. Human vascular permeability factor: isolation from U937 cells. J. Biol. Chem. 264:20017-20024.

34. Yanagisawa-Miwa, A., Y. Uchida, F. Nakamura, T. Tomaru, H. Kido, T. Kamijo, T. Sugimoto, K. Kaji, M. Utsuyama, C. Kurashima, and H. Ito. 1992. Salvage of infarcted myocardium by angiogenic action of basic fibroblast growth factor. Science (Wash. DC). 257:1401-1403.

35. Isner, J. M., and K. Rosenfield. 1993. Redefining the treatment of peripheral artery disease. Circulation. 88:1534-1557.

36. Ferrara, N., K. Houck, L. Jakeman, and D. W. Leung. 1992. Molecular and biological properties of the vascular endothelial growth factor family of proteins. Endocr. Rev. 13:18-32.

37. Lindner, V., D. A. Lappi, A. Baird, R. A. Majack, and M. A. Reidy. 1991. Role of basic fibroblast growth factor is vascular lesion formation. Circ. Res. 68:106-113.

38. Lindner, V. and M. A. Reidy. 1991. Proliferation of smooth muscle cells after vascular injury is inhibited by an antibody against basic fibroblast growth factor. Proc. Natl. Acad. Sci. USA. 88:3739-3743.

39. Flaumenhaft, R., D. Moscatelli, O. Saksela, and D. B. Rifkin. 1989. Role of extracellular growth factor for long-term stimulation of plasminogen activator production and DNA synthesis. J. Cell. Physiol. 140:75-81.

40. Fujita, M., S. Sasayama, H. Asanoi, H. Nakajima, O. Sakai, and A. Ohno. 1988. Improvement of treadmill capacity and collateral circulation as a result of exercise with heparin pretreatment in patients with effort angina. Circulation. 77:1022-1029.

41. Fujita, M., A. Mikuniya, M. Takahashi, R. Gaddis, J. Hartlen, D. McKown, and D. Franklin. 1987. Acceleration of coronary collateral development by heparin in conscious dogs. Jpn. Circ. J. 51:395-402.

42. Unger, E. F., C. D. Sheffield, and S. E. Epstein. 1991. Heparin promotes the formation of extracardiac to coronary anastomoses in a canine model. Am. J. Physiol. 260:H1625-H1634.

43. Soker, S., C. M. Svahn, and G. Neufeld. 1993. Vascular endothelial growth factor is inactivated by binding to $a_{2}$-macroglobulin and the binding is inhibited by heparin. J. Biochem. 268:7685-7691.

44. Klagsbrun, M., and J. Folkman. 1990. Angiogenesis. In Peptide Growth Factors and Their Receptors II. M. B. Sporn and A. B. Roberts, editors. Springer Publishing Company, New York. 459-586.

45. Shweiki, D., A. Itin, D. Soffer, and E. Keshet. 1992. Vascular endothelial growth factor induced by hypoxia may mediate hypoxia-initiated angiogenesis. Nature (Lond.). 359:843-845. 